\title{
Avaliações externas e a qualidade do ensino brasileiro
}

\author{
Fernanda Barros Ataídes ${ }^{1}$ \\ Anair Araújo de Freitas Silva ${ }^{2}$ \\ Cecília Vicente de Sousa ${ }^{3}$ \\ Ivana Ferreira dos Santos ${ }^{4}$
}

\begin{abstract}
Resumo. Atualmente, é muito preocupante o cenário educacional em que a avaliação externa vem assumindo um papel de centralidade em todo o processo educativo, pela forma como tem sido feita nas instituições escolares, geram efeitos ineficientes e ineficazes no processo de ensino. Desse modo, nas últimas décadas, observamos que houve uma intensificação do papel da avaliação externa nas políticas públicas educacionais no Brasil como propulsora da qualidade da educação. Essa avaliação se pauta no uso de testes padronizados, com resultados apresentados em forma de dados quantitativos com princípios de meritocracia, classificação, seleção, competitividade e perda de autonomia do/a professor/a. Nessa perspectiva, responsabilizam-se os/as professores/as e as escolas pelos resultados obtidos, eximindo-se os estados de seus compromissos com a educação. Além de serem instrumentos limitados e contraditórios, pois, não conseguem avaliar o processo educativo em sua totalidade. Nesse sentido, este estudo buscou analisar e refletir sobre a qualidade do ensino, a partir da ótica das avaliações externas. Na busca pela compreensão da temática proposta, optamos por conduzir uma pesquisa bibliográfica com base em uma abordagem teórica explicativa, em dialogo com pesquisadores/as do campo da avaliação. Em síntese, concluímos que os métodos avaliativos centrados nas avaliações externas oferecem uma educação empobrecida, pautada na memorização e no treinamento dos/as estudantes com o objetivo de alcançar altas pontuações, gerando consequentemente, um estreitamento curricular, ao focar o ensino apenas nas disciplinas de língua portuguesa e matemática.
\end{abstract}

Palavras-chave: Educação. Avaliações externas. Qualidade do ensino.

\section{External evaluations and the quality of brazilian teaching}

\begin{abstract}
Nowadays, the educational scenario in which the external evaluation is assuming a central role in the whole educational process, due to the way in which it is carried out in the school institutions, creates inefficient and ineffective effects in the teaching process. Thus, in the last decades, we have observed an intensification of the role of external evaluation in public educational policies in Brazil as a driver of the quality of education. This evaluation is based on the use of standardized tests,

\footnotetext{
${ }^{1}$ Mestre em Educação pela Universidade Federal de Uberlândia. fernandarv.ataides@ gmail.com

${ }^{2}$ Mestre em Educação pela Universidade Federal de Uberlândia. anairfs@ yahoo.com.br

${ }^{3}$ Mestre em Educação pela Universidade Federal de Uberlândia. ivana_iane@ yahoo.com.br

4 Mestre em Educação pela Universidade Federal de Uberlândia. figueira41@ yahoo.com.br
} 
with results presented in the form of quantitative data with principles of meritocracy, classification, selection, competitiveness and loss of autonomy by the teacher. In this perspective, teachers and schools are held accountable for the obtained results, and states are exempted from their commitments to education. Besides being limited and contradictory instruments, therefore, they can not evaluate the educational process in its entirety. In this sense, this study sought to analyze and reflect on the quality of teaching, from the perspective of external evaluations. In the search for understanding the proposed topic, we chose to conduct a bibliographic research based on an explanatory theoretical approach, in dialogue with researchers in the field of evaluation. In summary, we conclude that the evaluation methods centered on external evaluations offer an impoverished education, based on the memorization and training of the students with the objective of achieving high scores, thus generating a narrowing of the curriculum, focusing on teaching only in Portuguese language and mathematics.

Keywords. Education. External evaluations. Quality of teaching..

\section{INTRODUÇÃO}

O presente trabalho surge de inquietações e desconfortos vivenciados em nossa experiência profissional, tem como objetivo principal fazer uma reflexão acerca da qualidade do ensino brasileiro, centrado nas avaliações externas, de cunho neoliberal, que se solidificam sob valores quantitativos. Do ponto de vista neoliberal, para alcançar um ensino de qualidade, basta obter bons resultados em exames com parâmetros preestabelecidos. No entanto, nem sempre foi utilizado esse critério para indicar qualidade, visto que eles se alteram no tempo e no espaço, principalmente quando analisamos as transformações da sociedade contemporânea com suas novas demandas.

Logo, o debate do tema nos leva a algumas indagações: Será que essas avaliações definem de fato a qualidade do ensino? Será que os resultados das avaliações são objetos de análises, reflexões e discussões para melhoria da qualidade do ensino ou servem apenas para classificar, comparar e segregar escolas e alunos? Será que essas avaliações levam em consideração outros fatores que podem influenciar nos resultados?

Estudos recentes mostram que essas avaliações - não desmerecendo sua importância não conseguem analisar o processo em sua totalidade, sendo insuficientes na compreensão da qualidade do ensino. Pontuam que elas, da forma como vêm sendo compreendidas e 
utilizadas, servem apenas para classificar, selecionar, segregar escolas e alunos/as, responsabilizando as instituições escolares e professores/as pelos resultados obtidos.

Diante desde preâmbulo, o estudo busca realizar uma abordagem teórica explicativa sobre a qualidade do ensino brasileiro na perspectiva das avaliações externas, sob o ponto de vista de pesquisadores/as do campo da avaliação.

\section{Avaliação e controle da educação}

Desde meados da década de 1990, as escolas de educação básica têm sido foco das avaliações externas, notadamente com a criação do primeiro sistema de avaliação no Brasil - o Sistema de Avaliação da Educação Básica (Saeb) - , que, pela Portaria $n^{0}$ 482, de 7 de junho de 2013 (BRASIL, 2013), passou a ser constituído pela Avaliação Nacional da Alfabetização (ANA), Avaliação Nacional do Rendimento Escolar (Anresc) e Avaliação Nacional da Educação Básica (Aneb), que têm influenciado na organização da rotina escolar e nas práticas pedagógicas docentes, uma vez que causam pressão, geram competitividade e responsabilizam escolas e professores/as pelos resultados de fracassos ou sucessos escolares.

Sousa (2009) acentua que, para o Saeb, a avaliação é um instrumento de gestão educacional que possibilita compreender e intervir na realidade educacional para a condução de políticas educacionais pelo Estado. Entretanto, segundo a autora, o que estamos presenciando são ênfase nos produtos ou resultados; atribuição de mérito a alunos, instituições ou redes de ensino; dados de desempenho escalonados, resultando em classificação; dados predominantemente quantitativos e não articulados à autoavaliação; ampla divulgação dos resultados na mídia, favorecendo a classificação e a comparação.

Ao inserir o Estado neoliberal nessa discussão, Gentili (1996) acentua que ele

[...] é mínimo quando deve financiar a escola pública e máximo quando define de forma centralizada o conhecimento oficial que deve circular pelos estabelecimentos educacionais, quando estabelece mecanismos verticalizados e antidemocráticos de avaliação do sistema e quando retira autonomia pedagógica às instituições e aos atores coletivos da escola, entre eles, principalmente, aos professores. Centralização e descentralização são as duas faces de uma mesma moeda: a dinâmica autoritária que caracteriza as reformas educacionais implementadas pelos governos neoliberais (GENTILI, 1996, p. 27). 
Vê-se que são muitas as evidências de que, por trás de um discurso político que se sustenta na necessidade de melhorar a qualidade da educação, está a proposta de uma avaliação centralizada e descentralizada, ambas, não fazem sentido algum ao processo educativo, pois, são reformas autoritárias, vinda de cima para baixo, que não se preocupam com as necessidades do "chão da escola" constitui-se em meros " [...] mecanismo de controle, direcionado à mensuração do desempenho dos estudantes por meio de exames em larga escala [...]" e que se fundamenta "[...] na simplificação nas análises sobre a produção dos resultados escolares." (ESTEBAN, 2012, p. 576). Essa forma de pensar a educação imobiliza grande parte da criatividade de estudante e professores/as, e, para Afonso (2007), constitui um retrocesso, um verdadeiro atraso na vida de crianças e jovens, homens e mulheres da nossa sociedade:

\begin{abstract}
A adopção de certos dispositivos de avaliação externa (sobretudo os que são baseados em indicadores quantificáveis e mensuráveis) não contribuirá para a tão propagandeada melhoria da qualidade do ensino, representando antes um retrocesso político e educacional injustificável quando comparado com os progressos científicos e epistemológicos que têm vindo a conduzir a avaliação para perspectivas antipositivistas, mais complexas, pluralistas, democráticas e objetivas (AFONSO. 2007, p. 20).
\end{abstract}

Nessa via, mensurar a qualidade do ensino por meio de dados quantitativos é um equivoco, pois números são incapazes de medir o saber em construção, a educação emancipatória, o dia a dia de luta dos/as professores/as por uma escola plural e democrática.

No entendimento de Esteban (2012), a política de avaliação, ao mesmo tempo que simplifica processos complexos, não efetiva sua intenção de neutralidade e objetividade, pois "a técnica não é suficiente para eliminar a dimensão sociocultural do conhecimento, dos processos de sua socialização e validação ou mesmo das dinâmicas de aprendizagem" (ESTEBAN, 2012, p. 576).

Ao fazer uma análise crítica das provas de avaliação estandardizadas, Casassus (2009) constata que elas têm se afastado das finalidades que lhes são atribuídas socialmente. Ressalta que elas se converteram em meros instrumentos de ranqueamento, estabelecendo posições entre os sujeitos examinados e promovendo desigualdades e diminuição da qualidade da educação. Para o autor, é um erro acreditar que esse tipo de prova mede o que sabem e/ou que sabem fazer os alunos nas instituições escolares e erro ainda mais grave equiparar as 
pontuações obtidas a uma educação de qualidade, mesmo porque, como diz Afonso (2009, p. 13), "nem tudo o que conta em educação é mensurável ou comparável".

Pontuação não é qualidade. Qualidade não é pontuação. Uma educação de qualidade é o que se pode chamar de boa educação. Uma educação de qualidade tem a ver, essencialmente, com a capacidade que a instituição escolar tem para facilitar que as pessoas se transformem em melhores pessoas, que a sociedade se transforme em melhor sociedade. É uma actividade de conhecimento transformador (CASASSUS, 2009, p. 74).

Nessa perspectiva, uma boa educação não se resume em altas pontuações, uma boa educação é aquela que preza pela transformação da realidade educacional e garanta a aprendizagem de todos/as estudantes contribuindo para o desenvolvimento pleno dos/as estudantes. O ideal seria que essas avaliações externas se prestassem a observar, de fato, as especificidades e necessidades de cada instituição escolar, contribuindo para a transformação do processo, fazendo uso dos resultados para tomada de decisões. No entanto, a realidade é outra, geralmente os resultados são utilizados como mecanismo de classificação, seleção e controle do processo educativo. Mesmo diante desse contexto, reconhecemos a necessidade e importância desses processos avaliativos para a melhoria do ensino, como retrata Castro (2009, p. 34), para ele “os testes padronizados são instrumentos necessários, mas insuficientes para avaliar a melhoria da qualidade da educação [...], pois possuem um caráter restrito de avaliação", ou seja, as avaliações externas se bem utilizadas, tem a sua importância na melhoria do ensino, pois, pode trazer informações importantes que favorecem o planejamento e o repensar de ações no interior das escolas. O que não pode acontecer é fazer dela o único mecanismo para indicar qualidade, é necessário, estabelecer um diálogo com outros instrumentos capazes de abarcar toda complexidade do processo.

Contribuição importante a esse debate é dada por Iaies (2003, p. 18) quando argumenta que "os sistemas educativos deixaram de trabalhar para melhorar a qualidade e a equidade educativa e passaram a trabalhar para o melhoramento dos resultados das avaliações", acrescentando que "os dispositivos e seus produtos têm tido maior impacto na construção do imaginário educativo da sociedade, que na transformação das estratégias educativas". Assim, o que se percebe é que essa avaliação vem distorcendo das suas reais finalidades, sendo utilizada apenas para servir aos interesses de uma lógica mercadológica e ao capital, deixando em segundo plano práticas avaliativas a favor de uma educação 
emancipatória e comprometida com a transformação social, atribuindo uma supervalorização às avaliações externas com o mero objetivo de identificar posições e rankings, seguidos de responsabilização da escola e de seus profissionais por esses resultados.

É por esse ângulo que Brunner (2003) analisa a publicização dos resultados das avaliações em veículos de comunicação de massa, notadamente em jornais e revistas que se limitam a "ressaltar unidimensionalmente os produtos finais destes processos - a saber, os resultados enquanto pontuação - e a organizá-los em um esquemático ranking de países ou tipos de estabelecimento, suprimindo toda referência ao contexto onde se obtêm estes resultados". Com isso, conclui o autor, "se banaliza a informação que aportam os estudos nacionais e internacionais de medida do rendimento escolar e, o que é mais grave, se distorce a opinião pública e se limitam seus efeitos" (BRUNNER (2003, p. 81-82)

\subsection{Nexos entre avaliação e lógica de mercado}

Há de se considerar, que no contexto atual, houve profundas mudanças na educação brasileira, por meio de influências do neoliberalismo, da globalização, e da ação massiva dos organismos internacionais e transnacionais de "obsessão avaliativa" (AFONSO, 2007), com conexões entre avaliação e mercado, pois, "se é verdade [...] que emergiu o Estado-avaliador, também é verdade que as mudanças nas políticas avaliativas foram igualmente marcadas pela introdução de mecanismos de mercado" (AFONSO, 2009, p. 20) e isso explica, segundo o autor, o fato de o controle sobre os resultados escolares não ser subordinado nem restringido a uma mera lógica burocrática. Com isso, no campo educacional, o Estado passa a atuar como o centro da avaliação e dá destaque central às políticas de avaliação, envolvendo todos os níveis e etapas da educação, seguindo a lógica de "Estado Avaliador". O Estado sai dessa ideia de prestador de serviço, de pensar nas condições básicas de vida e passa a ter uma função regulatória, todavia, a questão é a centralidade e os interesses que o orienta.

Tanto é que, de acordo com Freitas (2007, p. 187), o Estado conseguiu legitimar "uma regulação avaliativa centralizada, externa aos sistemas e às escolas, e conduzida segundo princípios político-administrativos e pedagógicos que $[\ldots]$ enfatizaram a administração gerencial, a competição e a accountability, na perspectiva de uma lógica de mercado". 
No contexto educacional, segundo Brooke e Cunha (2011, p. 22), o termo accountability - comumente entendido como responsabilização das escolas, gestores e professores pelos resultados dos alunos - "significa acima de tudo a associação entre resultados de aprendizagem e consequências para o distrito educacional, a escola, os professores ou os alunos". Afonso (2009) o associa a três dimensões articuladas: prestação de contas, responsabilização e avaliação, que constituem o tripé de um processo de accountability.

$\mathrm{Na}$ esteira dos processos avaliativos e de responsabilização, o governo segue uma lógica de mercado que pode ser traduzida como uma espécie de "pedagogia de resultados", como diz Saviani (2007, p. 1253). Isso significa que

[...] o governo se equipa com instrumentos de avaliação dos produtos, forçando, com isso, que o processo se ajuste às exigências postas pela demanda das empresas. É, pois, uma lógica de mercado que, [...] assim como nas empresas, visa obter a satisfação total dos clientes e interpreta que, nas escolas, aqueles que ensinam são prestadores de serviço; os que aprendem (SAVIANI, 2007, p. 1253).

Nessa perspectiva, as práticas avaliativas deixam de se preocupar com o rendimento e aprendizagem dos/as estudantes, tornando-se meros instrumentos de fiscalização e controle da ação das instituições escolares. Com isso, certifica-se apenas a qualidade das escolas, gerando assim, uma competição entre as unidades, responsabilizando-as pelo sucesso e/ou fracasso escolar.

Referindo-se à noção de "quase-mercado" implantada no setor público e camuflada na intenção de promover melhorias, Sousa e Oliveira (2003, p. 877) afirmam que, "no caso da educação, os mecanismos que têm evidenciado maior potencial de se adequarem a ela são as políticas de avaliação, associadas ou não a estímulos financeiros”. Nesse sentido, explicam que essa lógica estimula a adoção de procedimentos competitivos entre escolas e sistemas para melhorar pontuações nos rankings definidos basicamente pelos desempenhos em instrumentos de avaliação. Essa competição ocorre "pela associação entre desempenho e financiamento, podendo redundar em critérios para alocação de recursos, que incidem, até mesmo, em remunerações diferenciadas dentro de sistemas de ensino que até a pouco trabalhavam com a noção de remunerações isonômicas" (SOUSA; OLIVEIRA, 2003, p. 877).

Freitas (2007), sinaliza que 
[...] o despontar da avaliação em larga escala como via de regulação central da educação básica não se subordinava à lógica do debate em defesa da escola pública e democrática, antes se orientou pelas ideias de modernização administrativa, cujas estratégias propiciaram a participação dos envolvidos segundo propósitos políticopedagógicos consequentes para os interesses predominantes no país (FREITAS, 2007 , p. 47-48)

Processos avaliativos são importantes para acompanhamento dos/as estudantes e dos/as professores/as na escola do dia a dia. Todavia, o que se discute não é a extinção da avaliação, mas a forma como ela é feita. Se comprometidos com uma educação emancipatória, esses processos podem ser usados, pela escola, para garantir a melhoria do processo. Mas essa visão democrática da educação não combina com as avaliações externas propostas pelo MEC, pois limitam o conhecimento dos/as estudantes.

Como consequência, "o que se vem evidenciando aos professores é o paradoxo entre vivenciar uma avaliação como atividade a serviço do desenvolvimento de todos os estudantes ou a serviço de prepará-los para os testes" (SOUSA, apud SCHNEIDER; ROSTIROLA; MOZZ, 2011, p. 311).

Já há pesquisas que tem mostrado que os professores tendem a ensinar para os testes, organizando suas propostas de ensino em razão do que será 'cobrado'. A ênfase nos produtos ou resultados educacionais, medidos por meio da aplicação de provas aos estudantes, que resultam em classificações, pode comprometer o processo de construção de uma avaliação que se coloque com finalidade formativa (SOUSA, apud SCHNEIDER; ROSTIROLA; MOZZ, 2011, p. 311).

Destarte, essas avaliações externas passam a orientar o que ensinar e como ensinar, gerando uma alienação e engessamento do fazer pedagógico, isto significa, que as escolas se submetem ao controle externo e abrem mão de sua autonomia (liberdade pedagógica e liberdade de conteúdo), porque tem que seguir um pacote padrão

Nesse sentido, Sousa e Arcas (2010, p. 187) afirmam que as políticas de avaliação "podem conter possibilidades emancipadoras ou virem a servir à intensificação das desigualdades educacionais e sociais, seus fins e meios e os usos de seus resultados são reveladores do real significado que assumem no processo educacional".

A avaliação "só ganha sentido quando subsidia intervenções que levem à transformação e à democratização da educação, em suas dimensões de acesso, permanência e qualidade" (SOUSA; OLIVEIRA, 2010, p. 818). Para isso, é necessária "uma ruptura com [a] concepção de avaliação de produto, com potencial de controle, que produz comparação e classificação, promovendo o individualismo e competição e, consequentemente, a 
discriminação e exclusão", substituindo-a por "uma avaliação que tenha um caráter processual, com potencial educativo, que produza reflexão e decisão, com base no diálogo e cooperação, capaz de promover a inclusão" (SOUSA, apud SCHNEIDER; ROSTIROLA; MOZZ, 2011, p. 313).

Nesse sentido, defendemos uma avaliação que, de fato, ajudem os/as professores/as a identificar falhas, desenvolver ações, para intervir e transformar a realidade. Uma avaliação que seja mais justa e humanística, pautada na igualdade e equidade de todos/as.

\section{CONSIDERAÇÕES FINAIS}

Os métodos avaliativos centrados nas avaliações externas continuam a oferecer uma educação empobrecida, pautada na memorização e treinamento dos/as alunos/as, infelizmente, essa é a triste realidade que estamos vivenciando nos dias atuais, ensejando-se num estreitamento curricular, em que os/as profissionais são condicionados/as a "ensinar para o exame", priorizando conteúdos propostos pelos testes e, consequentemente, deixando de lado o ensino emancipador que leva o/a estudante a pensar e a refletir sobre sua realidade.

Não queremos negar os processos avaliativos, pois o desempenho é um fator a considerar, e quando a avaliação está comprometida com uma educação emancipatória e com a resolução dos problemas que surgem durante o percurso escolar, ela é fundamental para alcançarmos uma educação de qualidade.

Contudo, para que essa avaliação se torne mais justa e garanta a aprendizagem de todos/as os/as estudantes, devemos levar em consideração outros condicionamentos que influenciam no processo, como fatores intraescolares - práticas docentes, métodos de ensino, recursos escolares disponíveis, ambiente escolar - e extraescolares - a situação socioeconômica dos/as alunos/as, o meio cultural e familiar, as políticas públicas, o contexto sociopolítico e econômico.

\section{Referências bibliográficas}


AFONSO, Almerindo Janela. Nem tudo o que conta em educação é mensurável ou comparável: crítica à accountability baseada em testes estandardizados e rankings escolares. Revista Lusófona de Educação, v. 13, p. 13-29, 2009. 22, 2007.

Estado, políticas educacionais e obsessão avaliativa. Contrapontos, v. 7, n. 1, p. 1-

ARAÚJO, Ivanildo Amaro de. Avaliação da educação básica: repercussões, tensões e possibilidades no currículo das escolas de periferia urbana. Espaço do Currículo, v. 6, n. 1, p.107-120, 2013.

BRASIL. Ministério da Educação. Portaria no 482, de 7 de junho de 2013. Dispõe sobre o Sistema de Avaliação da Educação Básica - Saeb. Brasília, DF: Ministério da Educação, 2013.

BROOKE, Nigel; CUNHA, Maria Amália de A. A avaliações externa como instrumento de gestão educacional nos estados. Estudos \& Pesquisas Educacionais, v. 2, p. 3-64, p. 17-79, 2011.

BRUNNER, José Joaquín. Límites de la lectura periodística de resultados educacionales. In: IAIES, Gustavo et al. Evaluar las evaluaciones: una mirada política acerca de las evaluaciones de la calidad educativa. Buenos Aires: Instituto Internacional de Planeamiento de la Educación - Unesco, 2003. p. 67-84.

CASASSUS, Juan. Uma nota crítica sobre a avaliação estandardizada: a perda de qualidade e a segmentação social. Sísifo, v. 9, p. 71-78, 2009.

CASTRO, Alda Maria Duarte Araújo. A qualidade da educação básica e a gestão da escola. In: FRANÇA, Magna; BEZERRA, Maura (org.). Política educacional: contextos e perspectivas da educação brasileira. Brasília, Liber Livro, 2009. p. 21-44.

ESTEBAN, Maria Teresa. Considerações sobre a política de avaliação da alfabetização: pensando a partir do cotidiano escolar. Revista Brasileira de Educação, v. 17, n. 51, p. 573$592,2012$.

FREITAS, Luiz Carlos de. Eliminação adiada: o caso das classes populares no interior da escola e a ocultação da (má) qualidade do ensino. Educação e Sociedade, v. 28, n. 100 Especial, p. 965- 987, 2007.

GENTILI, Pablo (org.) Escola S. A.: quem ganha e quem perde no mercado educacional do neoliberalismo. Brasília: CNTE, 1996.

IAIES, Gustavo. Evaluar las evaluaciones. In: IAIES, Gustavo et al. Evaluar las evaluaciones: una mirada política acerca de las evaluaciones de la calidad educativa. Buenos Aires: Instituto Internacional de Planeamiento de la Educación - Unesco, 2003. p. 15-35. 
SAVIANI, Dermeval. O plano de desenvolvimento da educação: análise do projeto do MEC. Educação e Sociedade, v. 28, n. 100 - Especial, p. 1231-1255, 2007.

SCHNEIDER, Marilda Pasqual; ROSTIROLA, Camila Regina; MOZZ, Gabriela Strauss Entrevista com a professora doutora Sandra Zákia Sousa: avaliações em larga escala e os desafios à qualidade educacional. Roteiro, v. 36, n. 2, p. 309-314, 2011,

SOUSA, Sandra Zákia. Concepções de qualidade da educação básica forjadas por meio de avaliações em larga escala. Avaliação, v. 19, n. 2, p. 407-420, 2014.

Possíveis impactos das políticas de avaliação no currículo escolar. Cadernos de Pesquisa, n. 119, p. 175-190, 2003.

SOUSA, Sandra Zákia; ARCAS, Paulo Henrique. Implicações da avaliação em larga escala no currículo: revelações de escolas estaduais de São Paulo. Educação: Teoria e Prática, v. 20, n. 35, p. 181-199, 2010.

SOUSA, Sandra Zákia; OLIVEIRA, Romualdo Portela de. Políticas de avaliação da educação e quase mercado no Brasil. Educação e Sociedade, v. 24, n. 84, p. 873-895, 2003.

SOUSA, Sandra Zákia; OLIVEIRA, Romualdo Portela de. Sistemas estaduais de avaliação: uso dos resultados, implicações e tendências. Cadernos de Pesquisa, v. 40, n. 141, p. 793822, 2010. 